\title{
Detection of CNV in the SH3RF2 gene and its effects on growth and carcass traits in chickens
}

\author{
Zhenzhu Jing ${ }^{1,2+}$, Xinlei Wang ${ }^{1,2+}$, Yingying Cheng ${ }^{1,2}$, Chengjie Wei ${ }^{1,2}$, Dan Hou ${ }^{1,2}$, Tong Li ${ }^{1,2}$, Wenya Li ${ }^{1,2}$, \\ Ruili Han ${ }^{1,2}$, Hong $\mathrm{Li}^{1,2}$, Guirong Sun ${ }^{1,2}$, Yadong Tian ${ }^{1,2}$, Xiaojun Liu ${ }^{1,2}$, Xiangtao Kang ${ }^{1,2}$ and Zhuanjian Li $\mathrm{i}^{1,2^{*}}$ (D)
}

\begin{abstract}
Background: The SH3RF2 gene is a protein-coding gene located in a quantitative trait locus associated with body weight, and its deletion has been shown to be positively associated with body weight in chickens.

Results: In the present study, CNV in the SH3RF2 gene was detected in 4079 individuals from 17 populations, including the "Gushi XAnka" F2 resource population and populations of Chinese native chickens, commercial layers, and commercial broilers. The F2 resource population was then used to investigate the genetic effects of the chicken SH3RF2 gene. The results showed that the local chickens and commercial layers were all homozygous for the wild-type allele. Deletion mutation individuals were detected in all of the commercial broiler breeds except Hubbard broiler. A total of, 798 individuals in the F2 resource group were used to analyze the effects of genotype (DD/ID/II) on chicken production traits. The results showed that CNV was associated with 2-, 6-, 10-, and 12-week body weight $(P=0.026,0.042,0.021$ and 0.039 respectively) and significantly associated with 8-week breast bone length $(P=0.045)$. The mutation was significantly associated with 8-week body weight $(P=0.007)$ and 4 -week breast bone length $(P=0.010)$. CNV was significantly associated with evisceration weight, leg muscle weight, carcass weight, breast muscle weight and gizzard weight $(P=0.032,0.033,0.045,0.004$ and 0.000, respectively).
\end{abstract}

Conclusions: CNV of the SH3RF2 gene contributed to variation in the growth and weight gain of chickens.

Keywords: Chicken, SH3RF2 gene, CNV, Growth traits, Carcass traits, Association analysis

\section{Background}

In recent years, with the development of the economy and the improvement of people's living standards, consumer requirements regarding the quality of poultry products, especially flavor and taste, have increased. Chinese local chickens have excellent characteristics, such as tender meat, good taste and unique flavor, which

\footnotetext{
* Correspondence: lizhuanjian@163.com

†Zhenzhu Jing and Xinlei Wang contributed equally to this work

'Department of Animal genetics and breeding, College of Animal Science and Veterinary Medicine, Henan Agricultural University, Zhengzhou 450046, Henan, China

${ }^{2}$ Henan Innovative Engineering Research Center of Poultry Germplasm Resource, Zhengzhou 450002, Henan, China
}

are favored by consumers. However, as growth traits and carcass traits are the main economic traits of poultry, the slow growth rates and low feed utilization rates of local chicken breeds in China represent limits to production. Therefore, genetic improvement through activities such as cultivating new varieties to increase the growth rate and the rate of lean meat gain in chickens has been a focus of research [1]. Thus, the use of modern molecular markers for marker-assisted selection and molecular breeding of chickens is important.

DNA molecular marker technology uses the gene library of the organism of interest without compromising the composition or expression of the genes [2]. It is a kind of

C C The Author(s). 2020 Open Access This article is licensed under a Creative Commons Attribution 4.0 International License, which permits use, sharing, adaptation, distribution and reproduction in any medium or format, as long as you give appropriate credit to the original author(s) and the source, provide a link to the Creative Commons licence, and indicate if changes were made. The images or other third party material in this article are included in the article's Creative Commons licence, unless indicated otherwise in a credit line to the material. If material is not included in the article's Creative Commons licence and your intended use is not permitted by statutory regulation or exceeds the permitted use, you will need to obtain permission directly from the copyright holder. To view a copy of this licence, visit http://creativecommons.org/licenses/by/4.0/ The Creative Commons Public Domain Dedication waiver (http://creativecommons.org/publicdomain/zero/1.0/) applies to the data made available in this article, unless otherwise stated in a credit line to the data. 
genetic marker technology that can be used to identify variation at the nucleic acid level that potentially reflects functional differences among individuals. Molecular marker technology is helpful in revealing differences in the composition or arrangement of the whole genome or variation at the nucleotide level within a gene, providing insight into DNA variability and polymorphism. It can also be used to identify individuals containing target genes by genotype analysis of closely linked genetic markers of target genes, which can help improve selection efficiency (e.g., by reducing blind search) and accelerate the breeding process [3]. Compared with the use of traditional genetic markers, molecular marker-assisted selection (MAS) provides many marker loci, a large amount of genetic information, and strong repeatability of experiments, and it is not susceptible to environmental impacts and has no limitations regarding sex and age. Therefore, MAS allows early selection, shortens the generation interval, improves the selection intensity, and thus improves the efficiency and accuracy of selection. Due to these advantages, MAS has broad application prospects for animal genetic improvement [4]. At present, the application of DNA molecular marker technology in poultry genetic breeding mainly comprises genetic diversity analysis, germplasm identification, genetic relationship research, genetic map construction, quantitative trait loci (QTL) mapping, genome wide association study (GWAS) and molecular marker-assisted breeding [5]. A large number of genetic polymorphisms, including single nucleotide polymorphisms (SNPs), insertions/deletions (indels) and copy number variation $(\mathrm{CNV})$, have been revealed in many species through whole-genome sequencing $[6,7]$. $\mathrm{CNV}$ is an important source of genetic variation [8]. CNV is the main form of genome structural variation, which refers to the insertion, deletion, duplication, translocation and derived chromosome structural variation of DNA fragments larger than $1 \mathrm{~kb}$ in the genome relative to the reference sequence of the genome [9]. Because many CNVs contain entire genes, they are more difficult to identify and type than SNPs and indel copy number variants. As a result, they affect organisms to a greater extent than do these other types of polymorphisms. CNV is an important source of genetic variation complementary to SNP. CNV is associated with not only disease and abnormal development in livestock and poultry but also physical appearance and many economic traits [10-13]. For example, Wright [14] found that the first intron CNV of the SOX5 gene is related to crown type. The bean crown mutation in the chicken is a dominant mutation, which greatly reduces the size of the bean crown, thereby reducing heat loss and preventing frostbite, and it is an adaptive characteristic of the chicken in a cold environment [14]. Dorshorst [15] found that the insertion of the endothelin 3 (EDN3) gene was the main cause of overstaining of the skin of the black chicken. Elferink [16] found that a segment comprising a chicken prolactin receptor in the Z-chromosome is associated with the growth of the chickenundefineds fast-andslow feather. Gorla [17] provided that a chicken CNV map based on the $600 \mathrm{~K}$ SNP chip array jointly with a genome-wide gene copy number estimates in a native chicken population. Other reports have shown two copy number variable genes associated with Marek's disease, namely frizzled family receptor 6 (FZD6) and LIM and senescent cell antigen-like domain 1 (LIMS1) [18, 19]. These findings indicate that $\mathrm{CNV}$ in a gene can have important influences on economic characteristics of poultry and enrich organismal diversity. To date, few studies have investigated the effects of $\mathrm{CNV}$ in the $\mathrm{SH} 3$ domain containing ring finger 2 (SH3RF2) gene on poultry growth and development. Rubin [20] resequenced the chicken genome and found a selective clearance region in many chicken genomes that included the SH3RF2 gene mutation site, which is located on chromosome 13, with all exons except the first exon being deleted. The total deletion length was $18,961 \mathrm{bp}$, and the gene was located in a body-related quantitative trait locus (QTL) range. The results of the study showed that the deletion mutation in the gene was positively associated with chicken body weight and fixed in the high-growth line of the broiler, appearing at lower frequencies in low-growth lines and commercial broilers, indicating that this deletion is closely related to broiler growth and body weight. Zhao [21] studied the frequency distribution of the indel mutation of the SH3RF2 gene in 15 local chicken species in China and found no local chickens with the deletion mutation. In this study, we tested the CNV genotypes of local chicken breeds, commercial broilers, commercial laying hens and the "Gushi $\times$ Anka" chicken F2 resource population to identify SH3RF2 gene mutations in the population and to analyze the association between $\mathrm{CNV}$ in this gene and chicken growth performance. The relationships between the CNV and growth and carcass traits of F2 resources in "Gushi $\times$ Anka" chickens showed that the SH3RF2 gene can be used as an effective marker for chicken production traits.

\section{Results \\ CNV genotyping}

After amplification, the "ins" (I) allele yielded only one $305 \mathrm{bp}$ fragment and was determined to be a nondeletion allele; individuals homozygous for this allele were assigned the II genotype. The "del" (D) allele yielded only one $416 \mathrm{bp}$ fragment and was determined to be a deletion allele; homozygous individuals were assigned the DD genotype. Individuals exhibiting both $305 \mathrm{bp}$ and 416 bp product bands were considered heterozygous and assigned the ID genotype (Fig. 1). 


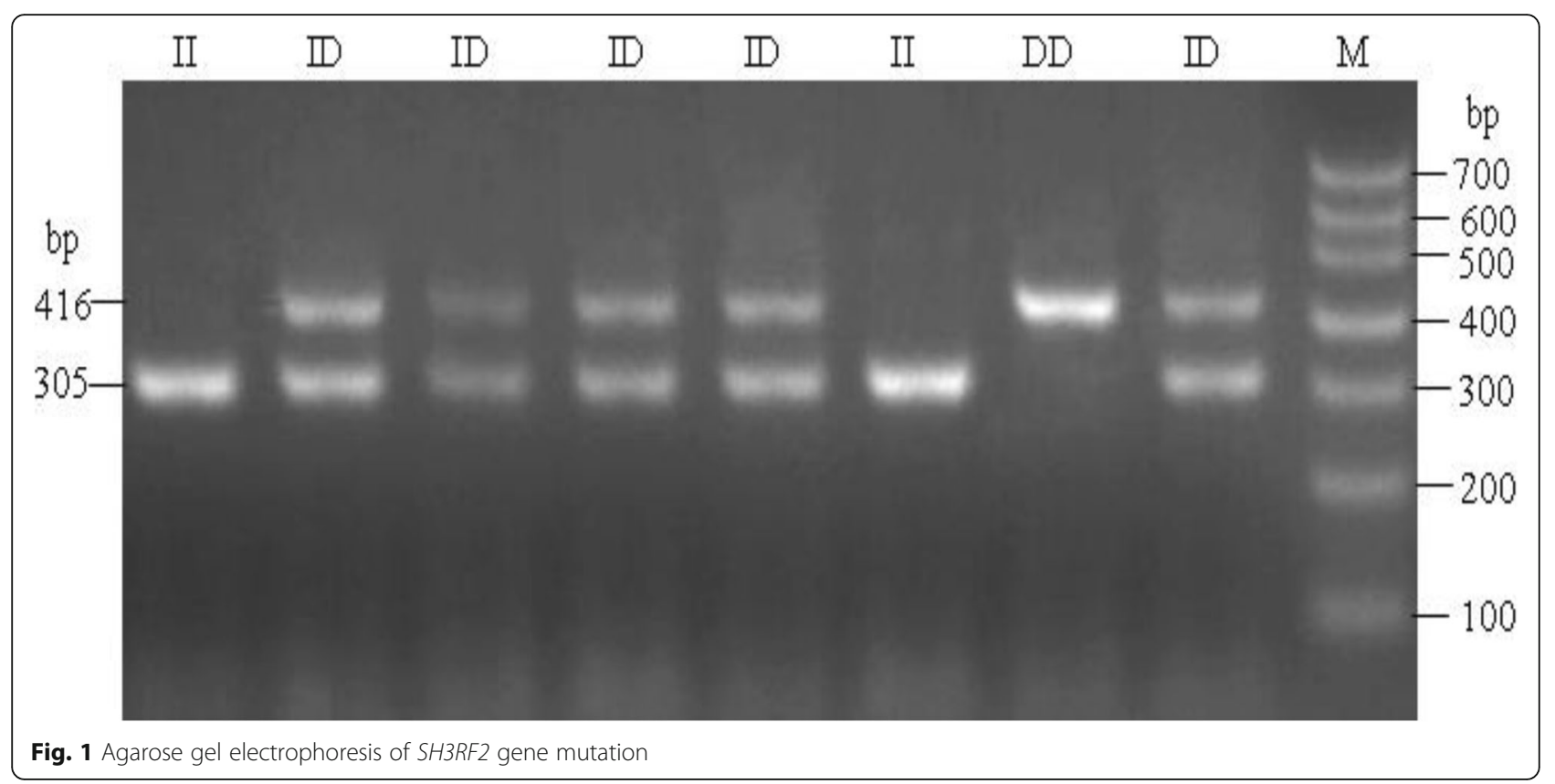

\section{Analysis of the genetic parameters of SH3RF2 gene mutations in different populations}

The distribution of SH3RF2 gene CNV genotypes and the gene frequencies in 4079 individuals from 17 populations were analyzed in this study (Additional file 1: Table S1). As shown in Table 1, there was a significant difference in genotypic frequency among the F2 resource population, AA broilers, $\mathrm{R} 308$ and $\mathrm{CB}$ broilers. ID genotypes and II genotypes were the predominant genotypes. The frequency of allele I was greater than that of allele $\mathrm{D}$, and the frequency of II genotypes was higher than the frequencies of ID genotypes and DD genotypes in each population. The frequency of the DD genotype was highest in the AA broiler group. The expected heterozygosity $(\mathrm{He})$ and number of allele $(\mathrm{Ne})$ values were $0-0.35$ and $1.00-$ 1.55, respectively. According to the standard polymorphism information and polymorphism information content (PIC), PIC $>0.50$ represents high polymorphism, PIC 0.25-0.50 represents moderate polymorphism, and $\mathrm{PIC}<0.25$ represents low polymorphism. The F2 resource group and AA broiler group showed moderate polymorphism, whereas the remaining populations showed low polymorphism.

\section{Association analysis of SH3RF2 genotype and growth traits in the $\mathrm{F} 2$ resource population}

As shown in Table 2, the growth traits of the F2 generation were significantly associated with SH3RF2 genotype. Genotype was significantly associated with $\mathrm{BW}$ at 2, 6, 8, 10 and 12 weeks $(P<0.05), \mathrm{BBL}$ at 8 weeks $(P<0.05)$, 8week BW $(P<0.01)$ and 4 -week BBL $(P<0.01)$. The
Table 1 Genotypic and allelic frequencies and related genetic parameters for the chicken SH3RF2 gene

\begin{tabular}{|c|c|c|c|c|c|c|c|c|}
\hline \multirow[t]{2}{*}{ Breed } & \multicolumn{5}{|c|}{ Genotypic and allelic frequencies } & \multirow[t]{2}{*}{$\mathrm{He}$} & \multirow[t]{2}{*}{$\mathrm{Ne}$} & \multirow[t]{2}{*}{$\mathrm{PIC}$} \\
\hline & $\mathrm{DD}$ & ID & $\|$ & $\mathrm{D}$ & 1 & & & \\
\hline$/ 798$ & 06 & 0.34 & 0. & 0.23 & 0.77 & 5 & 1.55 & 0.29 \\
\hline A/636 & 0.31 & 0.28 & 0.41 & 0.45 & 0.55 & 0.49 & 1.98 & 0.37 \\
\hline $08 / 238$ & 0.01 & 0.32 & 0.67 & 0.13 & 0.87 & 22 & 1.40 & 0.25 \\
\hline 3/193 & 0.16 & 0.01 & 0.83 & 0.17 & 0.91 & 0.09 & 1.10 & 0.15 \\
\hline 3D/282 & 0.00 & 0.08 & 0.92 & 0.04 & 0.96 & 0.08 & 1.08 & 0.07 \\
\hline $17 / 83$ & 0.00 & 0.30 & 0.70 & 0.15 & 0.85 & 0.26 & 1.34 & 0.22 \\
\hline & & & & & & & & $\begin{array}{l}0.00 \\
0.00\end{array}$ \\
\hline $5 / 17$ & 0.00 & 0.00 & 1.00 & 0.00 & 1.00 & 0.0 & 1.00 & 0.00 \\
\hline $5 / 144$ & 0.00 & 0.00 & 1.00 & 0.00 & 1.00 & 0.00 & 1.00 & 0.00 \\
\hline GF/18 & 0 & 0. & 1 & 0. & 1 & 0 & 1 & 0 \\
\hline$Y / 44$ & 0.00 & 0.00 & 1.00 & 0.00 & 1.00 & 0.00 & 1.00 & 0.00 \\
\hline$/ 20$ & 0.0 & 0.00 & 1.00 & 0.00 & 1. & 0. & 1.00 & 0.00 \\
\hline $\mathrm{WH} / 216$ & 0.00 & 0.00 & 1.00 & 0.00 & 1.00 & 0.00 & 1.00 & 0.00 \\
\hline 180 & ח ח & חת ח & 1.00 & ח & 1.00 & 0.00 & 1.00 & 0.00 \\
\hline $\mathrm{HL} / 456$ & 0.00 & 0.00 & 1.00 & 0.00 & 1.00 & 0.00 & 1.00 & 0.00 \\
\hline $\mathrm{LB} / 60$ & 0.00 & 0.00 & 1.00 & 0.00 & 1.00 & 0.00 & 1.00 & 0.00 \\
\hline
\end{tabular}

F2, AA, R308, CB, HBD, B817, RW, XC, GS, CS, GF, YY, LS, WH, GC, HL, and LB denote $\mathrm{F} 2$ resource population, Arbor Acres broiler, Ross308, Cobb broiler, Hubbard broiler, 817 broiler, Recessive white chicken, Xichuan chicken, Gushi chicken, Changshun chicken, Guifei chicken, Yunyang chicken, Lushi chicken, Wuhei chicken, Hy-line brown hen and Lohmann brown laying hen, respectively 
Table 2 Association analysis of CNV in the SH3RF2 gene and growth traits in the F2 resource population

\begin{tabular}{lllll}
\hline Traits & Mean \pm SE & & & \\
\cline { 2 - 4 } & II $(n=482)$ & D $(n=269)$ & DD $(n=47)$ & $\begin{array}{c}P \text { - } \\
\text { value }\end{array}$ \\
\hline BW2 (g) & $115.985 \pm 2.855^{\mathrm{ab}}$ & $122.347 \pm 1.162^{\mathrm{a}}$ & $123.847 \pm 0.861^{\mathrm{a}}$ & $324.787 \pm 2.115$ \\
BW4 (g) & $308.965 \pm 6.814$ & $322.282 \pm 2.814$ & $569.033 \pm 3.984^{\mathrm{a}}$ & 0.081 \\
BW6 (g) & $536.205 \pm 12.649^{\mathrm{ab}}$ & $563.207 \pm 5.306^{\mathrm{a}}$ & $826.332 \pm 5.989^{\mathrm{a}}$ & 0.042 \\
BW8 (g) & $762.844 \pm 19.211^{\mathrm{b}}$ & $817.485 \pm 7.894^{\mathrm{a}}$ & $1123.156 \pm 7.358^{\mathrm{a}}$ & 0.007 \\
BW10 (g) & $1055.384 \pm 23.335^{\mathrm{ab}}$ & $1113.946 \pm 9.888^{\mathrm{a}}$ & $1361.616 \pm 8.84^{\mathrm{a}}$ & 0.021 \\
BW12 (g) & $1287.379 \pm 27.936^{\mathrm{ab}}$ & $1358.504 \pm 11.755^{\mathrm{a}}$ & $7.947 \pm 0.029$ & 0.039 \\
SL8 (cm) & $7.713 \pm 0.094$ & $7.923 \pm 0.039$ & $5.698 \pm 0.025$ & 0.061 \\
CW8 (cm) & $5.548 \pm 0.082$ & $5.689 \pm 0.034$ & $3.439 \pm 0.01$ & 0.215 \\
SG8 (cm) & $3.377 \pm 0.033$ & $3.411 \pm 0.014$ & $6.267 \pm 0.023^{\mathrm{a}}$ & 0.079 \\
BBL4 (cm) & $6.061 \pm 0.074^{\mathrm{ab}}$ & $6.193 \pm 0.031^{\mathrm{a}}$ & $8.964 \pm 0.03^{\mathrm{a}}$ & 0.010 \\
BBL8 (cm) & $8.722 \pm 0.097^{\mathrm{ab}}$ & $8.908 \pm 0.04^{\mathrm{a}}$ & $11.475 \pm 0.036^{\mathrm{a}}$ & 0.045 \\
BSL4 (cm) & $11.154 \pm 0.118^{\mathrm{ab}}$ & $11.347 \pm 0.048^{\mathrm{a}}$ & 0.008
\end{tabular}

BW0, BW2, BW4, BW6, BW8, BW10, and BW12 denote body weight at 0 days, 2 weeks, 4 weeks, 6 weeks, 8 weeks, 10 weeks and 12 weeks, respectively. BW Body weight, $S L$ Shank length, $C W$ Chest width, SG Shank circumference, $B B L$ Breastbone length, $B S L$ Body slanting length. The same letters within a row indicate no significant difference $(P>0.05)$; different letters indicate significant differences $(P<0.05)$

growth trait values of the homozygous genotype DD were higher than those of the other two genotypes each week. The 8-week BW and 4-week BBL of individuals with the DD genotype were 92.3 and $97.2 \%$ higher, respectively, than those of individuals with the II genotype, indicating that the DD genotype is an economically dominant genotype. The growth trait values of the ID genotype were higher than those of the II genotype each week, indicating that allele $\mathrm{D}$ was the dominant allele.

\section{Association analysis of SH3RF2 genotype and carcass traits in the $\mathrm{F} 2$ resource population}

The association analysis showed that SH3RF2 genotype was significantly related to SEW, EW, SEP, EP, LMW, LWR, GWR and CW $(P<0.05)$ and MW, GW and BMWR $(P<0.01)$. Table 3 shows that the slaughter index of the different genotypes followed the order DD genotype > ID genotype > II genotype, which is consistent with the growth trait results.

Table 3 Association analysis of CNV in the SH3RF2 and carcass traits in the F2 resource population

\begin{tabular}{|c|c|c|c|c|}
\hline \multirow[t]{2}{*}{ Traits } & \multicolumn{3}{|l|}{ Mean \pm SE } & \multirow{2}{*}{$\begin{array}{l}P \text { - } \\
\text { value }\end{array}$} \\
\hline & $\|(n=482)$ & ID $(n=269)$ & $\mathrm{DD}(n=47)$ & \\
\hline$\overline{E W}(\mathrm{~g})$ & $870.526 \pm 20.885^{\mathrm{ab}}$ & $922.81 \pm 8.717^{a}$ & $928.011 \pm 6.63^{a}$ & 0.032 \\
\hline GW (g) & $25.955 \pm 0.674^{b}$ & $27.568 \pm 0.284^{b}$ & $28.450 \pm 0.214^{\mathrm{ab}}$ & 0.000 \\
\hline CW (g) & $1134.15 \pm 24.818^{\mathrm{ab}}$ & $1190.264 \pm 10.44^{\mathrm{a}}$ & $1198.651 \pm 7.936^{\mathrm{a}}$ & 0.045 \\
\hline MW (g) & $63.095 \pm 2.21 b$ & $71.055 \pm 0.918 a$ & $71.3 \pm 0.695^{a}$ & 0.002 \\
\hline SEW (g) & $1046.01 \pm 24.113^{\mathrm{ab}}$ & $1104.431 \pm 10.102^{a}$ & $1109.572 \pm 7.62^{a}$ & 0.042 \\
\hline LMW (g) & $141.966 \pm 3.465^{\mathrm{ab}}$ & $149.74 \pm 1.464^{\mathrm{a}}$ & $151.338 \pm 1.103^{\mathrm{a}}$ & 0.033 \\
\hline EP (\%) & $67.374 \pm 0.288^{\mathrm{ab}}$ & $67.829 \pm 0.121^{a}$ & $68.109 \pm 0.092^{\mathrm{a}}$ & 0.019 \\
\hline SEP (\%) & $81.075 \pm 0.288^{a}$ & $81.109 \pm 0.122^{\mathrm{ab}}$ & $81.54 \pm 0.092^{a}$ & 0.011 \\
\hline GWR (\%) & $2.016 \pm 0.045^{a}$ & $2.053 \pm 0.019^{a b}$ & $2.113 \pm 0.015^{\mathrm{a}}$ & 0.012 \\
\hline HWP (\%) & $3.311 \pm 0.048$ & $3.186 \pm 0.02$ & $3.208 \pm 0.016$ & 0.059 \\
\hline LWR (\%) & $2.246 \pm 0.045^{a}$ & $2.125 \pm 0.019^{\mathrm{ab}}$ & $2.145 \pm 0.015^{\mathrm{a}}$ & 0.048 \\
\hline BMWR (\%) & $14.383 \pm 0.267^{b}$ & $15.346 \pm 0.11^{\mathrm{a}}$ & $15.233 \pm 0.085^{\mathrm{a}}$ & 0.004 \\
\hline BWLP (\%) & $22.687 \pm 0.745$ & $23.738 \pm 0.313$ & $24.342 \pm 0.238$ & 0.053 \\
\hline
\end{tabular}

EW Evisceration weight, GW Gizzard weight, CW Carcass weight, $M W$ Breast muscle weight, SEW Semievisceration weight, LMW Leg muscle weight, EP Evisceration percentage, SEP Semievisceration weight rate, GWR Gizzard weight rate, HWP Head weight percentage, LWR Liver weight rate, BMWR Breast muscle weight rate, $B W L P$ Breast muscle water loss rate. The same letters within a row indicate no significant difference $(P>0.05)$; different letters indicate significant differences $(P<0.05)$ 


\section{Discussion}

Analysis of SH3RF2 gene polymorphism and the genetic population structure of different breeds of chickens The genetic resources of poultry species in China are diverse and contain great genetic variation and selection potential [22]. The vigorous development of animal husbandry will promote breeding efforts to improve the performance of chicken production [23]. Therefore, it is necessary to study the genetic variation of different chicken breeds. In this study, the frequencies of the DD genotype and D allele were lower than the other genotypes and I allele, respectively, in the studied populations, and few individuals with deletions were found among the populations of local and commercial layers. Whereas moderate polymorphism was found in the F2 resource population and the AA broiler, the remaining breeds showed low polymorphism. According to the polymorphism information content standard, this result indicates that the F2 resource population and AA broilers have greater selection potential in breeding and growth development efforts. In general, allele frequency reflects genetic diversity between populations. We found that allele D was the dominant allele in each population, suggesting that the gene did not undergo the same selection in the evolution of the different breeds of chicken. Moreover, artificial selection has a significant impact on the number of genes and distribution of genetic variation in different varieties [24]. We found that the frequency of DD genotypes was higher in commercial broiler populations with fast, large and high yields than that in other breeds, indicating that targeted breeding of commercial broiler chickens promoted the fixation of DD genotypes, which may be related to the rapid growth of commercial broiler chickens. We found no mutant deletion in commercial layers, which may be related to the selective breeding of layers.

\section{Associations between the SH3RF2 gene mutation and growth and carcass traits}

Body weight and body size are important indicators of the body development of poultry and are closely related to important economic characteristics [25]. To date, few studies on the SH3RF2 gene in poultry production have been conducted. Rubin [20] analyzed 400 chickens from F8 generations of high-growth and low-growth lines and found that the SH3RF2 gene deletion mutation had highly significant effects on chicken growth traits $(P<$ $0.01)$. In the present study, the F2 resource population of Anka and Gushi chickens was used to analyze the relationships between the SH3RF2 gene mutation and growth and carcass traits of chickens. Consistent with the previous study, the results showed that the mutation had significant influences on the growth and carcass traits of chickens. As poultry muscles are mainly distributed in the chest and legs, the yield of chest and leg muscles is an important factor determining the slaughtering performance of poultry and is one of the traits considered in poultry breeding [26]. In this study, SH3RF2 genotype was significantly associated with growth traits, such as BW and BBL, and slaughter indicators, such as GW, GW, LMW and CW $(P<0.05)$. In addition, individuals with the DD genotype had higher phenotype values than did individuals with II genotypes or ID genotype. The results show that the DD genotype has a significant dominant effect on traits of the F2 resource population.

\section{Conclusion}

This study found that CNV in the SH3RF2 gene was related to most of the studied growth traits and carcass traits in chickens. The results show that the mutation can be used for MAS breeding in chickens. Molecular breeding of chickens can reduce breeding costs, shorten the generation gap, and improve the efficiency of breeding to provide technical support for local chicken breeding in China.

\section{Methods}

\section{Experimental animals}

To identify the distributions of the different genotypes in different populations, individuals of the Gushi-Anka chicken F2 generation resource population, 8 local varieties, 5 chicken varieties and 2 layer varieties were investigated, with DNA samples collected from a total of 4079 individuals (Table 4). All blood samples were collected through the wing vein, after which 1:300 multidimensional hormone was used to reduce the stress response. Whole genome DNA was extracted from whole blood using the phenol-chloroform method. All chickens used in the study were healthy animals raised in the same environment with ad libitum access to feed and water. To produce the F2 resource population, two hatchings were obtained from an F1 generation constructed via reciprocal crossing between Chinese native Gushi chickens (representing a slow-growing Chinese native chicken) and Anka broilers (representing a fastgrowing broiler). Then according to a 1:9 ratio of males to females, an F2 generation was produced by mating the offspring with other family hens. The hens represented 7 families. The F2 generation was thus composed of 7 families, with Anka chicken as the male parent of 4 orthogonal lines and Gushi chicken as the male parent of the 3 reverse cross lines. We used an F2 resource family as previously described by Liang et al. [27] and Li et al. [28].

In henan provincial poultry germplasm resources innovation engineering research center, Gushi-Anka F2 resource population were housed in cages with 50 
Table 4 Information on the studied chicken breeds

\begin{tabular}{|c|c|c|c|c|c|}
\hline Breed & $n$ & Characteristic & Breed & $n$ & Characteristic \\
\hline F2 & 798 & segregating population & $X C$ & 260 & slow-growing, dual-type \\
\hline AA & 636 & fast-growing, meat-type & GS & 174 & slow-growing, dual-type \\
\hline R308 & 238 & fast-growing, meat-type & CS & 144 & slow-growing, dual-type \\
\hline $\mathrm{HBD}$ & 282 & fast-growing, meat-type & LS & 202 & slow-growing, dual-type \\
\hline $\mathrm{CB}$ & 193 & fast-growing, meat-type & YY & 44 & slow-growing, dual-type \\
\hline B817 & 83 & fast-growing, meat-type & WH & 216 & slow-growing, dual-type \\
\hline $\mathrm{HL}$ & 456 & egg-type & GF & 18 & slow-growing, dual-type \\
\hline$L B$ & 60 & egg-type & GC & 88 & slow-growing, game-type \\
\hline RW & 187 & slow-growing, dual-type & & & \\
\hline
\end{tabular}

F2, AA, R308, HBD, CB, B817, HL, LB, RW, XC, GS, CS, LS, YY, WH, GF, and GC denote F2 resource population, Arbor Acres broiler, Ross308 broiler, Hubbard broiler, Cobb broiler, 817 broiler, Hy-line brown hen, Lohmann brown laying hen, Recessive white chicken, Xichuan chicken, Gushi chicken, Changshun chicken, Lushi chicken, Yunyang chicken, Wuhei chicken, Guifei chicken, and Henan gamecock, respectively. "dual-type" denotes meat-egg-type

chickens per cage at $1 \mathrm{~d}$, providing $392 \mathrm{~cm}^{2}$ per bird. At the age of 8-week, it was transferred to three birds per cage $\left(448 \mathrm{~cm}^{2} /\right.$ bird). A total of 798 individuals from the F2 resource population were euthanised at $84 \mathrm{~d}$. In the laboratory of Henan Agricultural University, 5\% Pentobarbital $2 \mathrm{~mL}$ (No. 57-33-0 of Chinese Academy of Sciences, Beijing Siyuan Technology Co., Ltd.) was injected intraperitoneally into the Gushi-Anka F2 resource population. After 2-3 min of no spontaneous respiration, carotid artery bleeding occurred. Intraperitoneal injection of pentobarbital sodium can lead to rapid and relatively stress-free death. From hatch to slaughter, several chicken growth traits, including body weight and body size indexes, were measured. Each chicken was weighed every 2 weeks. Shank length was measured at $0,4,8$ and 12 weeks, and shank girth, chest depth, breast bone length, body slanting length and pelvis breadth were determined at 4, 8 and 12 weeks. Descriptions of the construction of the F2 population, feeding management and trait determination procedures can be found in a previous study [29, 30]. Information on 17 populations is presented in Table 4.

\section{Primer and PCR amplification}

The primers used in this study were all designed by Rubin [19] (Forward: 5'-TGCTTCGGGCTGAGCCTTCT-3', Reverse1: 5'-CGCCCAAGCTGTGTCCT-3', Reverse2: 5'CTGTCGGGCACGTGAGTGAA-3'). Assays were performed by PCR in a total volume of $10 \mu \mathrm{L}$ containing $5 \mu \mathrm{L}$ of $2 \times$ Taq Master Mix (Kangwei, Beijing, China), $0.5 \mu \mathrm{L}$ of forward primer, $0.5 \mu \mathrm{L}$ of reverse primer, $2.5 \mu \mathrm{L}$ of ultrapure water and $1 \mu \mathrm{L}$ of genomic DNA. The PCR amplification was performed as follows: $95^{\circ} \mathrm{C}$ for $5 \mathrm{~min}$ followed by $30 \mathrm{cy}$ cles at $95^{\circ} \mathrm{C}$ for $30 \mathrm{~s}, 64^{\circ} \mathrm{C}$ for $30 \mathrm{~s}$, and $72^{\circ} \mathrm{C}$ for $10 \mathrm{~min}$. The samples were then chilled at $4{ }^{\circ} \mathrm{C}$. To determine genotype, aliquots from each reaction $(7 \mu \mathrm{L})$ were subjected to electrophoresis in a $2 \%$ agarose gel.

\section{Statistical analysis}

Statistical analyses of the associations between genotype and the selected traits of the F2 chickens were performed using IBM SPSS (SPSS for Windows, Standard version 24; SPSS, USA). Genotype effects were analyzed by a multivariate linear model, and differences among genotypes were evaluated by Bonferroni's multiple comparison method. The analyses followed a previous study [31]. All data for each trait obtained by statistical analysis are presented as the mean \pm standard error (mean \pm SE). $P<0.05$ was considered to indicate statistical significance [32].

\section{Supplementary information}

Supplementary information accompanies this paper at https://doi.org/10. 1186/s12863-020-0831-z.

Additional file 1: Table S1. The Genotypic information on the studied chicken breeds. (XLS 234 kb)

\section{Abbreviations}

AA: Arbor Acres broiler; B817: 817 broiler; BBL: Breastbone length; BMWR: Breast muscle weight rate; BSL: Body slanting length; BW: Body weight; BWLP: Breast muscle water loss rate; CB: Cobb broiler; CHW: Chest width; CNV: Copy number variation; CS: Changshun chicken; CW: Carcass weight; EDN3: Endothelin 3; EP: Evisceration percentage; EW: Evisceration weight; F2: F2 resource population; FZD6: Frizzled family receptor 6; GC: Henan gamecock; GF: Guifei chicken; GS: Gushi chicken; GW: Gizzard weight; GWAS: Genome wide association study; GWR: Gizzard weight rate; HBD: Hubbard broiler; He: Expected heterozygosity; HL: Hyline brown hen; HWP: Head weight percentage; Indels: Insertions/deletions; LM: Lohmann brown laying hen; LMW: Leg muscle weight; LS: Lushi chicken; LWR: Liver weight rate; MAS: Marker-assisted selection; MW: Breast muscle weight; Ne: Number of allele; PCR: Polymerase chain reaction; PIC: Polymorphism information content; QTL: Quantitative trait loci; R308: Ross308 broiler; RW: Recessive white chicken; SE: Standard error; SEP: Semievisceration weight rate; SEW: Semievisceration weight; SG: Shank circumference; SH3RF2: SH3 domain containing ring finger 2; SL: Shank length; SNPs: Single nucleotide polymorphisms; WH: Wuhei chicken; XC: Xichuan chicken; YY: Yunyang chicken

Acknowledgements

We wish to thank our lab members for their helpful discussions. 


\section{Authors' contributions}

Conceived and designed the experiments: Z.Z.J, X.L.W, Z.J.L. Performed the experiments: Z.Z.J, C.J.W, D.H, T.L, W.Y.L, Y.Y.C. Analyzed the data: Z.Z.J, X.L.W, Z.J.L. Wrote the paper: Z.J.L, Z.Z.J. Oversaw the data collection process: R.L.H, H.L, G.R.S, Y.D.T, X.J.L, X.T.K. Contributed to final draft of paper: All authors. All authors read and approved the final manuscript.

\section{Funding}

This study was funded by resources from the Key Science and Technology Research Project of Henan Province (202102110085), National Natural Science Foundation of China-Henan joint grant (U1804107 and U1704233), National Natural Science Foundation of China (31872987), and Earmarked Fund for Modern Agro-Industry Technology Research Systems of China (No. CARS-40K04). The funding bodies had no influence on the design, acquisition, analysis, interpretation, nor presentation of the data and results of this study.

\section{Availability of data and materials}

All the data supporting the conclusions of the study are included in the manuscript and Additional file 1.

\section{Ethics approval and consent to participate}

All animal experiments and animal care methods were approved by the Institutional Animal Care and Use Committee (IACUC) of Henan Agricultural University, Zhengzhou, P.R. China (Permit Number: 11-0085) and were performed in accordance with the protocols outlined in the "Guide for Care and Use of Laboratory Animals" (Henan Agricultural University).

\section{Consent for publication}

Not applicable.

\section{Competing interests}

The authors declare that they have no competing interests.

Received: 18 December 2019 Accepted: 25 February 2020

Published online: 28 February 2020

\section{References}

1. Tallentire CW, Leinonen I, Kyriazakis I. Breeding for efficiency in the broiler chicken: Areview. Agron Sustain Dev. 2016;36(4):66

2. Vignal A, Milan D, Sancristobal M. André Eggen. A review on SNP and other types of molecular markers and their use in animal genetics. Genet Sel Evol. 2002;34(3):275-81.

3. Liu Z, Yang N, Yan YY, Li GQ, Liu AQ, Wu GQ, Sun CJ. Genome-wide association analysis of egg production performance in chickens across the whole laying period. BMC Genet. 2019;20(1):67.

4. Mahmoud KGM, Nawito MF. Molecular markers for fertility in farm animals. Iran J Appl Animal Sci. 2012;20(2):203-22.

5. Grover A, Sharma PC. Development and use of molecular markers: past and present. Crit Rev Biotechnol. 2014;36(2):1-13.

6. Mikkelsen TS, Hillier LW, Eichler EE, Zody MC, Jaffe DB, Yang SP, Enard W, Hellmann I, Lindblad-Toh K, Altheide TK, et al. Initial sequence of the chimpanzee genome and comparison with the human genome. Nature. 2005:437:69-87.

7. Begun DJ, Holloway AK, Stevens K, Hillier LW, Poh YP, Hahn MW, Nista PM, Jones CD, Kern AD, Dewey CN, et al. Whole-genome analysis of polymorphism and adivergence in Drosophila simulans. PLoS Biol. 2007:5:e310.

8. Conrad DF, Pinto D, Redon R, Feuk L, Gokcumen O, Zhang Y, Aerts J, Andrews TD, Barnes C, Campbell P, et al. Origins and functional impact of copy number variation in the human genome. Nature. 2010;464(7289):704-12.

9. Feuk L, Carson AR, Scherer SW. Structural variation in the human genome. Nat Rev Genet. 2006;7(2):85-97

10. Gao YH, Jiang JP, Yang SH, Hou YL, Liu GE, Zhang SL, Zhang Q, Sun DX. CNV discovery for milk composition traits in dairy cattle using whole genome resequencing. BMC Genomics. 2017;18(1):265.

11. Moro C, Cornette R, Vieaud A, Vieaud A, Bruneau N, Gourichon D, Bed'hom B, Boichard M. Quantitative effect of a CNV on a morphological trait in chickens. PLoS One. 2015;10(3):e0118706.

12. Han RL, Yang PK, Tian YD, Wang DD, Zhang ZX, Wang LL, Li ZJ, Jiang RR, Kang XT. Identification and functional characterization of copy number variations in diverse chicken breeds. BMC Genomics. 2014;15(1):934.
13. Zheng L, Xu JW, Li JC, Wang DH, An QM, Xu LN, Ma YL, Wang J, Peng SJ, Lei $C Z$, et al. Distribution and association study in copy number variation of KCNJ12 gene across four Chinese cattle populations. Gene. 2019;689:90-6.

14. Wright D, Bije H, Meadows JRS, Bedhome B, Gourichon D, Vieaud A, TixierBoichard M, Rubin CJ, Imsland F, Hallböök F, et al. Copy number variation in intron 1 of SOX5 causes the pea-comb phenotype in chickens. PLoS Genet. 2009;5(6):e1000512.

15. Dorshorst B, Molin AM, Rubin CJ, Johansson AM, Strömstedt L, Pham MH, Chen CF, Hallböök F, Ashwell C, Andersson L. A complex genomic rearrangement involving the endothelin 3 locus causes dermal hyperpigmentation in the chicken. PLoS Genet. 2011;7(12):e1002412.

16. Elferink MG, Vallée AA, Jungerius AP, Crooijmans RP, Groenen MA. Partial duplication of the PRLR and SPEF2 genes at the late feathering locus in chicken. BMC Genomics. 2008;9(1):391.

17. Gorla E, Cozzi MC, Román-Ponce SI, Ruiz López FJ, Vega-Murillo VE, Cerolini S, Bagnato A, Strillacci MG. Genomic variability in Mexican chicken population using copy number variants. BMC Genet. 2017:18(1):61.

18. Luo J, Yu Y, Mitra A, Chang S, Zhang M, Liu G, Yang N. Genome-wide copy number variant analysis in inbred chickens lines with different susceptibility to Marek's disease. G3 (Bethesda, Md.). 2013:3(2):217-23.

19. Yi G, Qu L, Liu J, Yan Y, Xu G, Yang N. Genome-wide patterns of copy number variation in the diversified chicken genomes using next-generation sequencing. BMC Genomics. 2014;15(1):962.

20. Rubin CJ, Zody MC, Eriksson J, Meadows JR, Sherwood E, Webster MT, Jiang L, Ingman M, Sharpe T, Ka S, et al. Whole-genome resequencing reveals loci under selection during chicken domestication. Nature. 2010;464(7288):587-93.

21. Zhao YJ, Zhang DX, Chen Y, Jia YX, Qu LJ. Study on the allele frequency distribution of an Indel of SH3RF2 gene in Chinese indigenous chicken breeds. Chinese Poultry. 2012;34(06):33-6.

22. Ma YL, Gu LT, Yang LB, Sun CH, Xie SS, Fang CC, Gong YZ, Li SJ. Identifying artificial selection signals in the chicken genome. PLoS One. 2018;13(4):e0196215.

23. Han RL, Li ZJ, Li MJ, Li JQ, Lan XY, Sun GR, Kang XT, Chen H. Novel 9-bp indel in visfatin gene and its associations with chicken growth. Br Poult Sci. 2011;52(1):52-67.

24. Han RL, Wang XN, Wang XL, Guo YP, Li DH, Li GX, Wang YB, Kang XT, Li ZJ. Chicken ZNF764L gene: mRNA expression profile, alternative splicing analysis and association analysis between first exon indel mutation and economic traits. Gene. 2019;695:92-8.

25. Allais S, Hennequet-Antier C, Berri C, Salles L, Demeure O, Le Bihan-Duval E. Mapping of QTL for chicken body weight, carcass composition, and meat quality traits in a slow-growing line. Poult Sci. 2019;98(5):1960-7.

26. Gaya LG, Ferraz JBS, Rezende FM. G B Mourão, Filho TM. Heritability and genetic correlation estimates for performance and carcass and body composition traits in a male broiler line. Poult Sci. 2006:85(5):837-43.

27. Liang K, Wang XN, Tian XX, Geng R, Li WY, Jing ZZ, Han RL, Tian YD, Liu XJ, Kang XT, et al. Molecular characterization and an 80-bp indel polymorphism within the prolactin receptor (PRLR) gene and its associations with chicken growth and carcass traits. 3. Biotech. 2019;9(8):296-306.

28. Li W, Liu D, Tang S, Li D, Han R, Tian Y, Li H, Li G, Li W, Liu X, Kang X, Li Z. A multiallelic indel in the promoter region of the Cyclin-dependent kinase inhibitor 3 gene is significantly associated with body weight and carcass traits in chickens. Poult Sci. 2019;98:556-65.

29. Wang XN, Li ZJ, Guo YP, Wang YB, Sun GR, Jiang RR, Kang XT, Han RL. Identification of a novel 43-bp indel in the heparan sulfate 6-Osulfotransferase 3 (HS6ST3) gene and its associations with growth and carcass traits in chickens. Anim Biotechnol. 2019;30(3):252-9.

30. Wang XN, Wang XL, Chen BJ, Guo YP, Tang HH, Li DH, Liu DL, Wang YB, Li GX, Kang XT, et al. Association of a new 99-bp indel of the CEL gene promoter region with phenotypic traits in chickens. Sci Rep. 2020;10(1):1-10.

31. Ren TH, Li WY, Liu DL, Liang K, Wang XN, Li H, Jiang RR, Tian YD, Kang XT, Li ZJ. Two insertion/deletion variants in the promoter region of the OPCTL gene are significantly associated with body weight and carcass traits in chickens. Anim Genet. 2019;50(3):279-82.

32. Liu D, Han R, Wang X, Li W, Tang S, Li W, Wang Y, Jiang R, Yan F, Wang C, et al. A novel 86-bp indel of the motilin receptor gene is significantly associated with growth and carcass traits in Gushi-Anka F2 reciprocal cross chickens. Br Poult Sci. 2019;60(6):649-58.

\section{Publisher's Note}

Springer Nature remains neutral with regard to jurisdictional claims in published maps and institutional affiliations. 